\title{
PRACTICES AND CHALLENGES OF GOVERNMENT SCHOLARSHIP FOR FOREIGN STUDENTS PROGRAMS IN EUROPEAN UNION, RUSSIA, AND CHINA: COMPARATIVE ANALYSIS AND LESSONS FOR UKRAINE
}

\author{
Galyna Solovey \\ PhD, Senior Lecturer, National University of Kyiv-Mohila Academy, Ukraine \\ e-mail: galasolo@yahoo.com,orcid.org/0000-0002-9535-4447
}

\section{Summary}

Existing Ukrainian governmental scholarship program for foreign students needs to be redesigned. Now Ukrainian scholarship program is not fulfill its main public diplomacy purpose, has problems with efficiency of budget allocation, and uses outdated selection process and ineffective administration. Potential candidates for Ukrainian scholarship program can also participate in the scholarship programs proposed by European Union, Russian Federation and Republic of China among others. Purposes, designs and administration of mentioned above three different scholarship programs for foreign students are analyzed using comparative method and official data from Ministries of education and international organizations. The main findings of this research could be recommendations for Ukrainian policy makers. 1) To separate scholarship programs for ethnic Ukrainians and foreign students; 2) to include but not to be limited by bilateral agreements in providing scholarships for foreign students; 3) to allocate budget for the scholarship program, not based by bilateral agreements; 4) to introduce non-degree scholarship programs, and 5) to incorporate international students into Ukrainian students' body.

Keywords: scholarship program, internationalization of higher education, students' mobility, public diplomacy, talent attraction

\section{DOI: https://doi.org/10.23856/3869}

\section{Introduction}

Nonetheless scope of reforms toward internationalization of Ukrainian higher education after 2014 is rather wide, there are many issues not had been tackled yet. One of those issues is redesigning existing Governmental Scholarship Program for Foreign Students (GSPFS), which was established almost three decades ago by Ukrainian Government Regulation from February 26, 1993 \#136. Regulation states, that Ukraine gradually should reduce number of full scholarships for international students (tuition, monthly allowance and medical insurance) who studied in the Ukrainian HEIs at the Soviet times from 11,200 in 1993/94; 7,100 in 1994/95; 3,200 in 1996/96; and 0,800 in 1996/97. Further scholarships for international students include only tuition-free placement in selected (high ranked) Ukrainian HEIs (neither monthly stipend no medical insurance are included) and should be provided on the basis on bilateral agreements with partner countries and the number of scholarship should not exceed 1,000. Regulation does not state the goal for scholarship provision for international students. Formulation of clear purpose for GSPFS is necessary for monitoring its effectiveness and efficiency; goal defines design and administration of the program. For redesigning GSPFS, Ukrainian government should establish clear goal of scholarship provision for foreign students and propose appropriate way of scholarship administration. 
Design and administration of existing Ukrainian GSPFS is outdated and ineffective. Existing GSPFS targets different groups: out of 1000 scholarships 300 are provided for overseas Ukrainians, 700 are to be used in bilateral agreements for students' exchange with foreign partners (post-Soviet states, developing and developed countries);

Ukrainian GSPFS is based on bilateral agreements which can be initiated by Ministry of Foreign Affairs (MOFA) for deepen mutual understanding with the foreign country or by MOE for educational exchange purpose. Bilateral agreements in education sphere are prepared by MOEs, are revised by MOFAs, both in Ukraine and in foreign countries.

Administration of Ukrainian GSPFS is the same as in former USSR. Candidates should be selected in the sending countries by the MOE of selecting country, revised by Ukrainian Embassy documents, are transferred to Ukrainian MOE. Candidates should submit hard copies or originals of the documents, making personal visits to officials. Electronic way of application is not used.

This research in analyzing the purposes, designs, and ways of administration of existing GSPFSs in three countries: Russia, China, and supranational scholarship program Erasmus + functioning in EU education space. Design of scholarship programs and their effectiveness in achieving the main purpose will be looked at from the point of view if such design and way of processing can be used for redesigning Ukrainian GSPFS. Russia was chosen as the inheriting Soviet type of GSPFS country which now is also modernizing its higher education system in accordance to the Bologna Process. Russian GSPFS is devoted to spread Russia's interests among the potential leaders of foreign countries. China was one of the allies of the former USSR and its higher education was build upon the Soviet model, very similar to the Soviet heritage of Ukraine. Powerful governmental intervention and presence of clear vision of internationalization cause significant up-bottom process of transformation of Chinese higher education. Chinese GSPFSs serve definite political role and are well managed. Management of scholarship programs and their segmentation for different target groups can bring a lot of lessons to Ukrainian policy makers in the sphere of education. Erasmus+ scholarship is designed and funded by supranational entity European Union with purpose to integrate European countries via students' mobility. Ultimately Poland, western neighbor of Ukraine, EU member from 2004, took the design of Erasmus+ scholarship as a basis for national GSPFS based on bilateral agreement with EU and non EU partners.

Which purposes have GSPFSs in different countries? How different GSPFSs are designed and administrated? How international experience can be used for redesigning Ukrainian GSPFS?

Qualitative comparative method of three countries' (Russia, China, and Ukraine) and one supranational union' (European Union) GSPFSs will be utilized. We will compare purposes, designs, and administration of GSPFSs.

Research consists of three parts: introduction where the purposes of the study and research questions are formulated. In the main part purposes, designs, and different ways of administration of GSFSPs are discoursed. Three countries' and EU' cases will be analyzed on the basis of theoretical framework designed according to the key factors related to establishing GSFSPs. This chapter covers comparative analysis of the goals and specific designs of GSFSPs in EU, Russia, China and Ukraine. The aim of comparison is identifying specific features of GSFSPs, which could be useful for redesigning GSFSP in Ukraine. In the concluding part according to the research findings, policy recommendations for redesigning GSFSP in Ukraine are provided. 


\section{Basic concepts and theoretical framework for GSPFS analysis}

Understanding of basic concepts is essential before making comparative analysis of the purposes, design and management of GSPFS in three selected countries.

Here we will understand internationalization of higher education and scholarship programs creation by the governments of different countries as the mean to reach national goals, which varies from country to country and changes with the time. Hudzik underlines that "not only internationalization is the mean rather than the end but the ends can vary from institution to institution, and the particular approach to the internationalization chosen is dependent on the ends being pursued." (Hudzik, 2011: 6).

Discussing provision of scholarship programs by one country to selected others we would understand this activity in the context of public diplomacy (open and seen by everyone diplomatic activity) which purpose is to promote friendly relationship between countries and to accept values and culture of the host country by students from sending countries (Lindsey, 1989).

We define governmental scholarship program for foreign students (GSPFS) as specially designed and managed by the government of host country activity which serves to fulfill specific purpose by provision of higher education on tertiary level (undergraduate, graduate and $\mathrm{PhD}$ ). Designs and management of GSPFS completely depend on the purpose for which host country introduces GSPFS.

Establishing GSPFS has significant goal for inviting country and such goals in national states differ from the period and from historical context. Why national states establish scholarship programs for foreign citizens?

Analyzing Soviet (1945-1990) and US (1948-present) GSPFSs Tsvetkova (Tsvetkova, 2008) states ideological goal of such programs to establish friendly political regimes in foreign states though legitimizing competing ideological values among influential (or potentially influential in the long run) groups in foreign countries. US educated over 600,000 of international leaders, academy stuff and students in the period of 1948-1990 and USSR educated over 500,000 international students in the same period. US and USSR were promoting market economy and democracy in the first case and planed economy and socialist ideas in the second case.

US Fulbright Scholarship targeted three main groups: leaders (politicians, civil society representatives and journalists), academy stuff and students from the existing political elites and representatives of upper-middle class whose chances to hold leading political position in the future were high. Analyzing US National Archives in Washington, Tsvetkova founds that the goal of Fulbright Scholarship program in the period of Cold War was to "implant the democratic principles of management, politics, and life within the professional group and other citizens in their own countries (Tsvetkova, 2008: 207).

USSR targeted working class representatives. Social background and pro-socialist way of thinking were the criteria, which overweighed academic achievements. Graduates from the Soviet HEIs received not only diplomas; they were formed to become socialist way of life propagandists in their home countries. Final goal for USSR GSPFS was formulated in long-term strategy of the Central Committee of Communist Party in 1962-66: "Our goal is to select and educate foreign people from lower classes, mainly from families of technicians. This policy will result in establishing new loyal generation of technocrats who will gain political power in almost all countries throughout the world by 2010 " (Tsvetkova, 2008: 206). 
Healy emphasizes activeness of US, UK and USSR in the period of Cold War providing governmental scholarships for foreign students and calls it "inexpensive way of securing the future loyalty of client states" (Healy, 2008: 334).

In the global context of $1945-90^{\text {th }}$ achievements in science and technology were reflected in national power, and beginning of transition to knowledge economy and knowledge-intensive industries which required intensification of informational exchange had place, 5 countries leaded in the number of international students in their higher education institutions (HEIs). McMahon (1992) proves that participation in international studies worldwide in this period was highly depended from country's relative political and economic position within the world system. Trade and political relation were the strongest factors to pull international students from source countries to the particular world center. At the time of the Cold War the principal rationale for the internationalization of higher education were peace and mutual understanding. Questions of national security and foreign policy were the main drivers for establishing scholarships and programs for foreign students (de Witt and Merkx, 2012: 49).

In late $1980^{\text {th }}$ understanding of European integration' prevalence on the top level of political power occurs. Higher education becomes the key channel to promote common European values among European states. In 1987, it materializes in students' mobility Erasmus program. Goals for higher education cooperation in Europe are following:

"To promote universal, normative values among the education community;

To set and monitor common (or shared) goals for education systems;

To develop comparable quality standards and performance indicators;

To enhance a policy dialogue and disseminating good practices at country and regional levels;

To provide financial aid for system governance through institutional development;

To promote the European dimension of education through student/stuff mobility and institutional networking" (Jallade, 2011: 7-8).

Beginning from 1987 students' mobility program is functioning in the common European education space. For its $30^{\text {th }}$ anniversary, more than $3,000,000$ students were involved in the process. Erasmus scheme concentrates on individual, institutional, national (promotion of diversity of European countries, internationalization of students' body, improving quality of higher education); regional (promotion of common European values, formation of European citizenship), and global (straitening of competitiveness of European higher education on the global scale) levels. HEIs of different European countries should establish mobility partnerships, compare and recognize curricula for credit mobility. Students participating in the process sign agreement with home and abroad university for credit transfer. Several institutions create broad networks having hundreds of partner institutions throughout Europe. Ukraine became a partner country for Erasmus $+2014-2020$ program, taking $48 \%$ of the entire budget for partner countries allocated and has 7000 one-semester scholarships for Ukrainian students mobility.

New purpose for establishing GSPFS, except of political, arises in the new millennium: talent attraction. Scholarship provision for exceptionally talented foreign students on the global scale can be seen as formation of elite skilled global workforce, which will serve to enhance competitiveness of the nation states and their economic growth. (Boun and Kim, 2011; Paik, 2015; Wei, 2013).

Different goals, designs and administration of GSPFS was not analyzed using comparative method yet. This research tries to explore various GSPFSs with the aim to understand how goals of national governments (supranational government in case of EU) defines design and 
administration of GSPFSs and how redesigning of Ukrainian GSPFS can serve the goals of Ukrainian government.

\section{Selection of the countries and theoretical framework}

Ukraine has 70 years' Soviet history and inherited Soviet educational system becoming independent state in August 24, 1991. After Revolution of Dignity in 2014 and outbreak of undeclared Russian-Ukrainian war, all the efforts of Ukrainian government at whole and Ministry of Education and Science particularly are to integrate to European community. European integration in the sphere of higher education does not mean unification. Reforms of national education inspired by Bologna process emphasize HEIs autonomy, credit counting according to ECTS (European Credit Transfer System), number and content of concentrations which ease for Ukrainian as well as for European students to take part in Erasmus mobility program (1987now). Ukraine takes part in Erasmus+ students' mobility program 2014-2020. 7000 Ukrainian students can take part in the program during this period. Erasmus mobility program propose one semester study for the students who completed at least one academic year in their own university in other European university with which home university has bilateral partnership agreement. Erasmus program gives strong motivation for Ukrainian HEIs to develop and maintain broad network of European partner institutions.

Russia is perceived by most countries of the world as the successor of USSR's power. It is worth to mention, that Russia nowadays provides 15000 scholarships for foreign students each year. Purpose for this scholarship is the same that in former USSR, slightly reformulated: formation of pro-Russian national elites who can effectively promote Russian interests in the international arena. Scholarship program is not based on bilateral agreements (but such agreements signed previously are taken into consideration), it is well promoted and candidates are not supposed to go through MOEs of sending countries. Candidates for the scholarship are selected by Russian Embassies and branches of company named Rossotrudnichestvo (organization for cultural cooperation) created in 2008. Now numerous Rossotrudnichestvo Centers are functioning in 77 countries in all regions of the world. After internet based application submission, interview in the Rossotrudnichestvo and exams are provided. Russian GSPFS does not have exclusively diplomatic goal as agents of Rossotrudnichestvo specially hunt for national and international science and mathematics Olympiads' winners and patent registered school graduates and offer them scholarships for studying in the high ranked Russian universities providing jobs in the future.

Chinese GSPF created in 1950-now on the basis of USSR' GSPFS has the diplomatic goal of mutual understanding and establishing of friendly relationship via providing education on tertiary level. Chinese GSPFS is based on bilateral agreements; candidates for scholarship are preselected by recipients' countries' MOEs, after which are selected by Chinese Embassy. Scholarship provides tuition free study on all three post-secondary levels (bachelor, master, $\mathrm{PhD}$ ), accommodation, monthly allowance, medical insurance for 10,000 (cumulative number) foreign students. GSPF is quite effective and efficient (Dong \& Chapman, 2008) serving political and long run economic (talent attraction) goals. Design of this scholarship has one similar feature with Ukrainian GSPFS - it is based on bilateral agreements. Nevertheless, way of administration of the scholarship is different and analysis of it can be useful for Ukrainian policy makers.

This paper will compare purposes, designs and administration of GSPFS of Russia, China, and Erasmus+ student mobility program of supranational entity European Union. Purpose of the GSPFS defines its design, administration and target groups of students. 


\section{Comparative analysis of GSPFSs in EU, Russia, China and Ukraine}

\section{Purposes of GSPFs}

Public Diplomacy Purpose

As we can see all scholarships analyzed have the public diplomacy purpose. For this purpose students should receive education in the host country and promote interests of the host country coming back home. Tsvetkova, N. (2008), Dong L. and Chapman D. (2008) use the quantity of scholarships alumnae holding the key positions back in their sending countries as the main indicator of success for Russian GSPFS in the first case and for the Chinese one in the second. The qualitative analysis of satisfaction surveys of international students participating in GSPFSs is essential for the evaluation of scholarship programs because unsatisfied students can negatively affect the image of the scholarship and the image of the host country as a whole, destroying the mere purpose for establishing GSPFS. Impact of Ukrainian GSPFS for the public diplomacy purpose was not analyzed yet.

Erasmus + scholarship fully satisfies the public diplomacy purpose giving its participants a chance to study in another European country during one semester. One-semester study is offered more often on the undergraduate level (usually students move using Erasmus + scholarship during 6-th semester of their bachelor studies) broadens students' cultural understanding and formulates their "European mindset". At the same time, Erasmus+ scholarship maintains students in the universities of their host countries and prevents brain drain from the less developed European countries to the developed ones. Degree mobility for Master's and PhD studies allows a student to move between two or more universities and have two academic supervisors having in a result joint diploma of two or more universities.

\section{Internationalization of Higher Education of the Host Country Purpose}

For the purpose of internationalization of higher education of the host country by inviting international students and formulation of the "global mindset" for the domestic students, who can receive it communicating with internationals, scholarship receivers should be fully integrated in the students' body, having the same language of instruction, using the same facilities and enjoying the same extra curricula activities sharing the time with domestic students.

Out of the four GSPFSs analyzed only Erasmus+ program fully and immediately integrates foreign students proposing courses, using the same language of instruction as it is used for domestic students. International students use the same facilities and participate in the same activities that domestic ones.

In the case of Russian and Chinese GSPFSs one- or two-years Russian or Chinese language courses are proposed for students who are not fluent in Russian or Chinese before degree program starts. Dong L. and Chapman D. (2008) mention that in the case of Chinese GSPFS foreign students live in separate dormitories enjoying better facilities ant treatments than domestic ones. In the case of English language of instruction' courses in Russian Federation more than in China foreign students are separated from domestic ones, so internationalization purpose for "formulation of the global mindset" for domestic students fails. For Russian GSPFS in the case then the language of instruction is Russian foreign students are integrated in the same groups with domestic ones. Mostly these students are from post-Soviet republics and do not need additional year of Russian language course having good knowledge of Russian from schools in their home countries.

For foreign students' integration into the students' body of the host country knowledge of the host countries' language of instruction is essential. Ukrainian GSPFS does not propose free 
旁

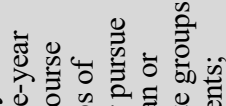

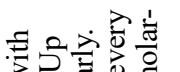

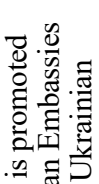

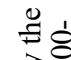

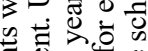

可

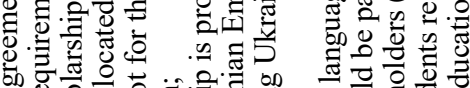
寓 군.

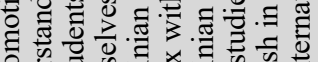

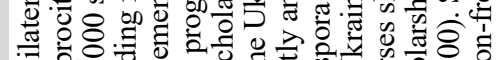

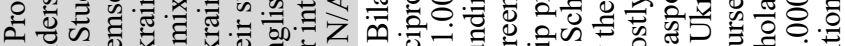

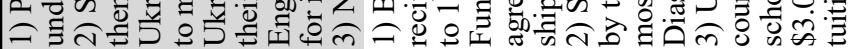

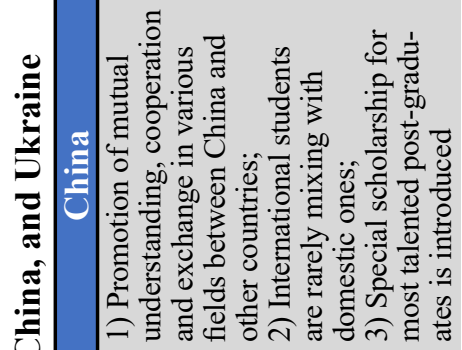

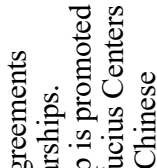

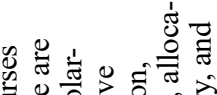

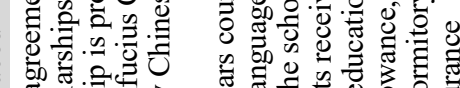

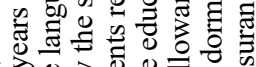

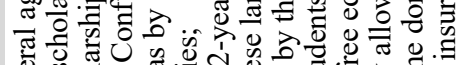

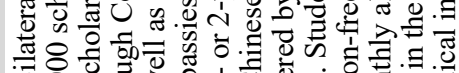

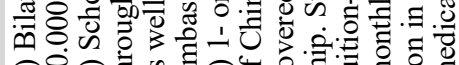

풍 焉

要

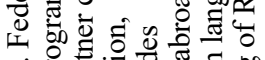

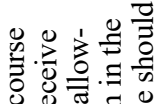

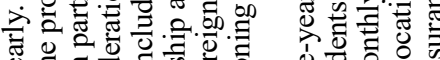

는요 久े

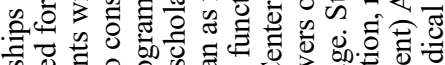

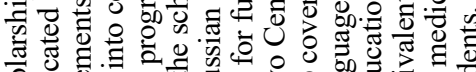
胥导 क.

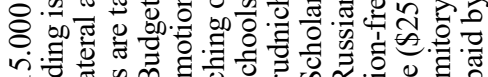

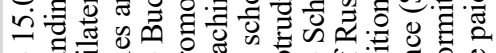

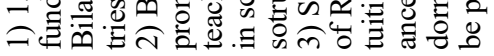

章

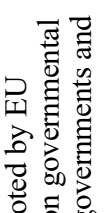

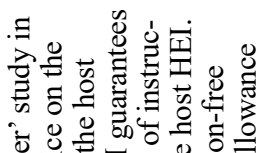

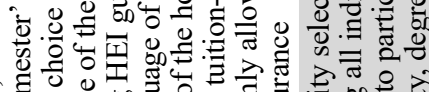

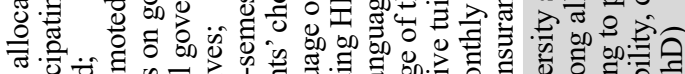

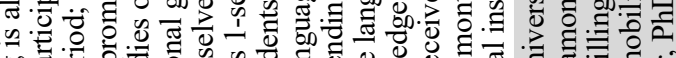

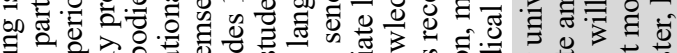

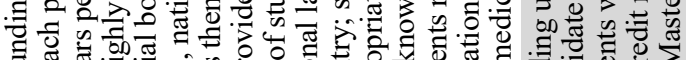

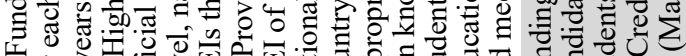

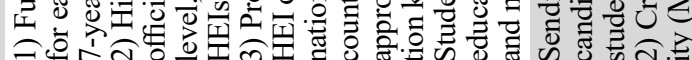
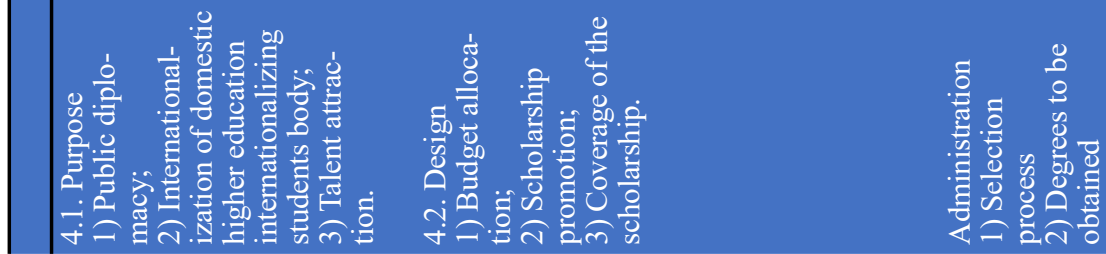
language course. Foreign scholarship recipients should pay for one-year Ukrainian language course equivalent of $\$ 1.000$ to $\$ 3.000$. In addition, programs in Russian and English are proposed in Ukrainian HEIs. By the Ukrainian legislation, Ukrainian citizens can receive higher education only in Ukrainian (this legislation was adopted in the early 1990-th for protection of Ukrainian language mostly replaced by Russian in the higher education). Russian-speaking foreign students (mostly from post-Soviet countries) and English-speaking students are forming separate groups, not integrating in the Ukrainian students' community.

\section{Talent attraction purpose}

To fulfill attraction of talented students' purpose in science intensive fields of knowledge several key requirements should be satisfied. Knowledge intensive industry of the host country should be developed, funded by the government and be of national priority. Host country should satisfy needs of talented students in development of their talents competing with other developed countries which can formulate the better offer in the same field of study and research. For this purpose European Union and China have separate scholarships. In the case of EU Erasmus Mundus joint $\mathrm{PhD}$ programs are proposed, in the duration of which $\mathrm{PhD}$ students have two consultants in two European universities and pursue their studies in both of them. In China separate from bilateral agreements scholarship for postgraduate talented students was introduced. Selection process for it is done by the universities where students should directly apply avoiding bureaucratic procedures in the embassies or MOEs of home and host countries.

In Russia in the framework of the only GSPFS, for talented graduates after the degree obtaining, working places in the knowledge intensive industries are proposed which produces additional attraction to the GSPFS in general.

For Ukrainian GSPFS talent attraction purpose is not relevant for now taking into account poor research funding by the government.

\section{Design}

\section{Budget allocation}

For Erasmus + program budget is allocated for 7-years' period and quantity of students moving from participated countries is distinguished. In Russian Federation' case budget is allocated yearly for 15.000 students from undistinguished countries. For Chinese scholarship budget is based on the quantity of students and programs allocated in the bilateral agreements with the partner countries.

In the case of Ukraine budget is allocated yearly for the quantity of students distinguished in bilateral agreements with the partner countries. Those agreements should be of the governmental level signed by Prime Ministers (or Ministers of Education, or Ministers of Foreign Affairs) and reinforced by 5-years Protocols among MOEs, distinguishing the quantity of students and specifying conditions of the scholarships. Those Protocols should be analyzed and approved by Ukrainian Ministries of Justice, Foreign Affairs, Economy, and the Ministry of Finance before signing. At the same time to be approved by Ukrainian ministry of Justice, such agreements should contain reciprocity requirements, which narrow the circle of potential partner countries to the states which are willing and able to propose places for Ukrainian students in their HEIs.

Nonetheless, bilateral agreements are the good way of friendly relationships demonstration, in the case of Ukraine bureaucracy takes such a lot of time and efforts from the both sides of the agreement that sometimes the public diplomacy purpose could not be fulfilled. Bilateral agreement as a basis for GSPFS should not contain obligatory reciprocity requirement which will give the space for Ukrainian diplomats to propose places in Ukrainian HEIs as a 
demonstration of friendly relationships in the diplomatic dialogue with the representatives of the countries which are unable to propose the same.

Ethnical Ukrainians, citizens of foreign countries, can participate in the same Ukrainian GSPFS as the foreign citizens of non-Ukrainian ethnicity not on bilateral agreement basis but with the condition of obtaining in Ukrainian Embassy status of Foreign Ukrainian.

\section{Scholarship Promotion}

In the case of Erasmus+ program, it is promoted on the supra-national level by EU administrative bodies, on the national level of participating countries and by HEIs themselves. HEIs are establishing numerous international contacts, and students' exchange intensity under Erasmus + scheme is one of the key indicators of HEI' internationalization.

Russian GSPFS is promoted by Russian Embassies in the foreign countries and by Rossotrudnichestvo centers in 77 countries in all the regions of the planet. Russian Embassies and Rossotrudnichestvo Centers are devoted to promote learning of Russian language in schools and often propose courses of Russian language out of schools preparing potential students to study in Russia using GSPFS or on self-funded basis.

Chinese GSPFS is promoted by Chinese Embassies and by Confucius Institutes abroad in more than 100 countries in all the regions of the world. Confucius institutes are not only propose information about Chinese HEIs which participate in GSPFS but also provides courses of Chinese language and possibility to pass the exam which will be accepted by Chinese HEIs in case if potential candidate for the scholarship will learn Chinese before coming to study in China.

Ukrainian GSPFS is promoted by Ukrainian Embassies abroad mostly among Ukrainian Diasporas. Ethnical Ukrainians can participate in the same scholarship too if obtaining the status of the Foreign Ukrainian. Learning of Ukrainian language and culture is promoted on the voluntary basis by huge Ukrainian Diasporas, standards of Ukrainian language as foreign is formulated by Ukrainian MOE several years ago, but officially promotion of Ukrainian language and culture abroad is Ukrainian Ministry of Culture' field of responsibility. This is the reason why Ukrainian language courses are not spread abroad using one standardized test which would prove level of language proficiency and would give its' completers rights to participate in Ukrainian GSPFS.

\section{Coverage of the Scholarships}

One of Erasmus + scholarship requirements is the previous students' acquisition of high level knowledge of the host HEIs' language of instruction. Only students who meet this requirement can participate in the students' mobility program. Russian GPSFS proposes one-year language course and Chinese GPSFS offers one- or two-year language courses depending on the subject of study.

Ukrainian GPSFS does not propose free of charge language courses.

All analyzed scholarships propose tuition-free study during the scholarship period. Erasmus+, Russian and Chinese GPSFSs also offer monthly stipend Chinese scholarship provides allocation and medical insurance. Ukrainian GPSFS does not provide three last components.

\section{Administration \\ Selection process}

In the case of Erasmus+ scholarship there are a lot of requirements to be fulfilled before students could participate in students' credit mobility. First of all Erasmus + scholarship requires acceptance of credit mobility scheme by participating countries. In addition, it 
requires partnerships establishment among HEIs into European education space and with HEIs of the non-EU Partner countries. So students studying in the particular HEI in the country that accepts credit mobility can move only to international HEIs with which their alma-mater HEI established partner relationship. Student willing to participate in Erasmus + scheme sign the agreement with their HEI and with international HEI about credit mobility and knowledge of the language of instruction of international HEI. Final decision of accepting candidates for the Erasmus + mobility program takes the home-country' HEI. Academic excellence, social activeness, motivation, and future usage perspectives of mobility experience should be taken into consideration. All those factors help administration to make a right choice.

To be accepted for Russian GSPFS candidates should pass through entering exams formed by Rossotrudnichestvo Centers. After this stage, candidates should pass examination of their HEIs and documents' review by Russian MOE. This two-stage process guarantees high quality of accepted candidates.

In the case of Chinese Bilateral Agreement GSPFS and Ukrainian GSPFS only documents of candidates are analyzed and choice is made on previous academic performance and motivation letter.

\section{Degrees to be obtained}

EU offers two types of mobility: credit and degree mobility. Both types of mobility serve to unify European educational space. Credit mobility can be executed on bachelor and masters levels. Degree mobility is used for graduate Master and PhD programs. Russian GSPFS offers places on all three levels. Chinese GSPFS offers three levels' programs and numerous non-degree programs which are most popular among students from EU, US, and other developed countries.

Ukrainian GSPFS offers places for Bachelor' and Master' programs.

\section{Conclusions}

Analysis of purposes, designs and administration of EU Erasmus student mobility, Russian and Chinese GSPFSs brings several lessons to be learned to develop new Ukrainian GSPFS.

\section{Purpose for Ukrainian governmental scholarship}

Ukrainian GSPFS should serve public diplomacy purpose deepening mutual understanding between Ukrainians and students from participating countries. Internationalization of domestic education purpose could reinforce the main purpose with the condition that international students will be integrated into the students' body of Ukrainian HEIs. For this reason 1) Ukrainian students should be encouraged to take courses in English in the same groups with international ones as English is the language of global scientific communication; 2) Free of charge one-year Ukrainian language course for degree scholarship holders should be provided after which international students should be mixed with domestic ones. Scholarship program for ethnic Ukrainians should be operated separately because it has different purpose and different target group.

\section{Design of Ukrainian governmental scholarship}

All analyzed GSPFSs have their origins in bilateral agreement design which completely fulfilled the public diplomacy purpose in the past century. The process of signing bilateral agreement was the result of long preparation and diplomatic negotiations. Nowadays 
students' exchange can be initiated by HEIs themselves and for public diplomacy purpose not the fact of signing agreement on the highest level but formation of youth loyal to the host country has the most valuable impact of the scholarship. New Ukrainian GSPFS should take into account previously signed bilateral agreements but at the same time propose places to the students from all the countries with which Ukraine has diplomatic relationships without signing special agreements.

Budget for the GSPFS should be allocated based on the scholarship program not for each bilateral agreement separately. Taking into account Ukrainian strategic goal to integrate to European community, Ukrainian GSPFS should particularly target EU students with non-degree short-term courses popularizing Ukraine as destination for Erasmus + students' mobility. Ukrainian as foreign language test should be introduced as soon as possible making short-term (from 4 weeks to one-year) scholarship programs for studying Ukrainian language and culture possible.

\section{Administration of Ukrainian governmental scholarship}

Selection process should be organized based on internet usage, allowing scholarship candidates to send copies of the documents via e-mail, and make skype interview before final enrolment decision.

\section{References}

De Wit, H. \& Merkx, G. (2012). "The history of internationalisation of higher education" Deardorff, D., de Wit, H., Heyl, J. \& Adams, T. (Eds.). The SAGE handbook of international higher education Thousand Oaks, CA: SAGE. (pp. 43-59).

Dong, L. \& Chapman, D. (2008). The Chinese Government Scholarship Program: An Effective Form of Foreign Assistance? International Review of Education / Internationale Zeitschrift Für Erziehungswissenschaft / Revue Internationale De L'Education, 54(2), 155-173.

Healey, N. (2008). Is Higher Education in Really 'Internationalising'? Higher Education, 55(3), 333-355.

Hudzik, J. K. (2011). Comprehensive internationalization: From concept to action. Washington, DC: NAFSA: Association of International Educators.www.nafsa.org/uploadedFiles/NAFSA Home/Resource_Library_Assets/Publications_Library/2011_Comprehen_Internationalization.pdf

Jallade, J. (2011). International Approaches to Education: A review of some major cooperative programmes. European Journal of Education, 46(1), 7-24.

Lindsay, B. (1989). Integrating International Education and Public Diplomacy: Creative Partnerships or Ingenious Propaganda? Comparative Education Review, 33(4), 423-436.

McMahon M. E. (1992). Higher Education in a World Market: An Historical Look at the Global Contest of International Study, Higher Education, 24 (4), 465-482.

Tsvetkova, N. (2008). International Education during the Cold War: Soviet Social Transformation and American Social Reproduction. Comparative Education Review, 52(2), 199-217. 